\title{
New strategic goals and organizational solutions in large R\&D labs: lessons from Centro Ricerche Fiat and Telecom Italia Lab
}

\section{Fabrizio Cesaroni ${ }^{1}$, Alberto Di Minin² and Andrea Piccaluga $^{3}$}

\author{
${ }^{1}$ Sant'Anna School of Advanced Studies, Piazza Martiri della Libertà 33, 56127 Pisa, Italy \\ cesaroni@sssup.it \\ ${ }^{2}$ Berkeley Roundtable on the International Economy, University of California, 2234 Piedmont \\ Avenue, Berkeley, CA 94720, USA \\ adminin@uclink.berkeley.edu \\ ${ }^{3}$ Dipartimento di Studi Aziendali Giuridici ed Ambientali, University of Lecce, Ecotekne, Via per \\ Monteroni, Lecce, Italy \\ a.piccaluga@economica.unile.it
}

\begin{abstract}
The issue of corporate $R \& D$ management has become particularly relevant during the last decade, since many industrial sectors experienced growing complexity in their research areas and increasing constraints in budgets devoted to $R \& D$ activities. This paper discusses the cases of the ICT and automotive sectors, exploring the changes in managerial procedures and strategies that two of the largest corporate research centres in Italy (Telecom Italia Lab and Centro Ricerche Fiat) adopted during a delicate phase of transition.

Both cases are characterized by a growing pressure towards the effective integration of short-term and long-term perspectives, i.e. towards a balance between valorization of research results and competencies, and exploration of new technological trajectories. The solutions adopted by the two organizations are explored and discussed. Specifically, while TiLab focused on the promotion of controlled spin-off companies, CRF has been very active in local technology transfer, especially in favour of SMFs.
\end{abstract}

\section{Introduction}

$\mathrm{T}$ he objective of this paper is to discuss the broad issue of the definition of robust strategies for large R\&D centres and analyse two specific different sets of strategies adopted in two of the largest industrial laboratories in Italy, during an interesting phase of transition. The first case study regards the Fiat Research Centre (Centro Ricerche Fiat - CRF) which is active in a broad range of automotive-related technologies. Its main peculiarity lies in its capacity of keeping the same level of activities (and personnel) during severe financial and market crises 
which the Fiat Group experienced in the last years (and at present). As a matter of fact, CRF is now well placed to pursue further growth strategies and keep increasing its knowledge base despite the current international crisis in the automotive sector. The second case refers to the R\&D organization of the largest Italian telecommunication operator and former monopolist (Telecom Italia Lab - TiLab). In the period of time that we took into account (1999-2001), this centre has undergone several reorganization efforts. Two were the main driving forces of these changes. The first is a challenge shared by other international TLC R\&D centres as well, and has to do with the attempt to integrate the development of information and telecommunication technologies. The second driver is unique to Telecom Italia, as these reorganizations mainly correspond to ownership changes. The owner of the laboratory used to be the State, then a private entrepreneur managed to buy out the Group, and finally the Pirelli Group got in control of Telecom Italia. In this process, various attempts have been made to transform a centre characterized by scientific excellence in a quasi-for profit research centre. Other important organization changes are going on at present, and their analysis goes beyond the purpose of this study. Only a few years from now it will become possible to understand where these changes are taking the Group to.

Both the automotive and the telecommunication sectors have experienced complex and distinct dynamics, characterized by sectoral deregulation and an increasing integration of TLC and IT technologies, in the case of the telecom sector, and by a decline in world demand and an increasing product complexity, in the case of the automotive sector. These changes have led to significant reorganization processes and difficult strategic decisions in the two cases, including a rethinking of their research centres' role. The struggle to keep structural costs as low as possible obliges firms to define ambitious expectations for their R\&D labs, i.e. to guarantee both long term technology-based growth opportunities as well as short term revenues. TiLab and CRF experienced exactly such a cultural change, since they ceased to be cost centres, and became autonomous business units, with the goal of producing cash flows in order to justify expenses. Hence, our research hypothesis is that, in both cases, managers had to face the fact that an investment in R\&D could not possibly be justified with a courageous exploration of technology trajectories. Exploration and exploitation could not possibly be seen as conflicting missions for the R\&D lab, since today they have to fulfil both of them.

Nonetheless, important differences do exist in the two cases, and especially in the events that determined the change in their corporate missions and in the strategies adopted for their accomplishment. CRF has been very active in local technology transfer, especially in favour of SMFs - most of which operating as suppliers in the automotive sector - often through the transfer of human resources, and the charismatic leadership of its CEO was of fundamental importance. TiLab's strategic reorientation has been somehow more complex and certainly more corporate-led, surely influenced by changes in corporate governance; it was based, among other factors, on the promotion of spin-off companies.

The role played by these two large research centres in the Italian national innovation system is very important, due to the fact that there are only a few laboratories in the country with more than 1000 people. Most of these labs used to operate in rather stable markets, with relevant resources for exploration activities and a not very demanding corporate level. On the contrary, at present, the customer, mainly the corporate level, is much more likely to finance projects whose goal is the exploitation of measurable, short term results with a consistent value added. Obviously, the risk of this orientation is excessive short-termism and the impoverishment of competencies and abilities to be trend-spotters in the long period.

Two events determined radical changes in the strategies adopted in the two R\&D laboratories under study.

The first one is the crisis of the Fiat Group in the early nineties. During this crisis all Fiat Group companies started a radical restructuring process to regain competitiveness. However, CRF management asked the corporate level to access a broader, non-Group market for its technological assets and competencies, in order to be able to demonstrate that it could survive without any downsizing. The decision was not easy to take, but the lab was finally allowed to do so and since then it sells research to a broad range of companies, obviously keeping in touch with the mother company, which has a first-option privilege.

In the second case, the nineties brought an important element in the TLC sector. The 1996 Telecommunications Deregulation Act in the USA testified that the deregulation and privatization of the market was on its way. The EU undertook this process as well. In 1997 the Open Network Provision substituted the 1987 Green 
Book (which recognized the necessity of a monopoly at least for the network and the infrastructures). Every country member was strongly advised to open the TLC market to competition as soon as possible. The 1997 directive regulates the free access to the networks and a precise interconnectivity policy, the use of European standard to create an integrated continental network. New competition on the domestic markets and new possibilities on the foreign markets have then become important incentives for the search of an equilibrium between exploration and exploitation, between the production of market-ready solutions and a broader analysis of the foreseeable technological paths. The exploitation of $R \& D$ activities and projects therefore became a priority and a difficult task for TiLab. The main problem is the fact that the typical suppliercustomer relationship is not fully compatible with the typical interactions that occur between a company and its research lab. No matter the strategic decision of the management, the client that belongs to the same industrial group is a very peculiar type of customer. TiLab was used to have abundant budgets to carry out long-term research, and had to adapt to a new operating framework.

\section{The rethinking of $R \& D$ activity within corporate strategies and organizations}

During the nineties, a vast literature has focused on the structural changes that corporate $R \& D$ management has experienced. Researchers have described these changes in both their technological and strategic nature. Many industrial sectors experienced growing complexity in their research areas. In particular, the most significant and widespread phenomenon has been the integration of various technological realms for the same applications. The integration with information technologies has been the most significant example (Rao, 1999). A second, vastly discussed change, has been the growing attention to the costs of corporate $\mathrm{R} \& \mathrm{D}$ activities (Rao, 2000). The largest corporations were the first organizations which had to adopt strategic, often radical solutions.

Empirical evidence shows that these changes did not necessarily led to disinvestments in $R \& D$, but certainly determined significant reassessments of the innovation strategy (Duysters and Hagedoorn, 1996). There is broad agreement on the fact that the emergence of international and national strategic technological partnerships has been the most common reaction to these changes. A study of the World Bank (Vonortas and Safioleas, 1997), tried to empirically map partnerships in the IT sector, showing a clear increase in recent times. Other case studies (among others, Granstrand, 1999), explain the specific benefits connected with international R\&D cooperation. Traditionally, it has been argued that the emergence of collaboration in the R\&D sector was unlikely, due to high transaction costs (Mowery, 1995). Rao (1999) argues that the rise of technological complexity may represent the incentive to overcome the difficulties, risks and costs involved. In fact, as complexity increases, it becomes more profitable to establish technological partnerships with competitors, suppliers and clients, and to focus on a specific technological core (Chiesa et al., 1999), rather than to try and make everything 'in-house'. It has also been pointed out (Godoe, 2000), that one of the most important consequences of this international division of labour, is the increasing risk of a technological 'lock in' effect when the 'core' leads the research centre, and its partners, along the wrong technological trajectory. A partial solution to this problem is the focus on 'diversity within the network', which is considered to be an important drive for R\&D productivity.

The automotive and TLC sectors are among the most innovative industries in the manufacturing and service sectors (Evangelista and Sirilli, 1998), and they were both affected by these transformations. The driver for change was not only growing technological complexity. These two industries were also affected by growing competition, the liberalization of the TLC market, and decreasing operative margins in the automotive industry (Lera, 2000).

Two were the main streams of the debate resulting from these changes. The first one focused on the measurement of the R\&D investment assessment. The second had to do with the analysis of the consequences on the company's innovativeness, of an R\&D more exposed to market pressure. Both these two fields provide the most important research questions that need to be addressed by researchers.

In fact, researchers have long been debating about how to measure and assess R\&D investment, and this activity has become more and more important in industrial $\mathrm{R} \& \mathrm{D}$ organization. The net present value approach, focused on the definition of sound parameters to estimate risk discount rates. Due to the nature of R\&D investment and returns, this method produced 
unsatisfactory results. New approaches, such as the calculation of the option value, try to overcome this problem, with more complex stochastic models (Pennings and Lint, 1997). Another approach (see Ransley, 1994 and Rush et al., 1995) used a benchmarking technique to measure and evaluate performances and choices of R\&D labs and researchers.

As for the second research question, authors think that, in order to cope with shortening product development cycle times and decreasing budgets, R\&D investments need to be focused on the most immediate needs of customers (Cooper et al., 1998). It has been argued that markets are usually very good in matching supply and demand, but they are bad advisers when the firm is trying to define its R\&D strategy (Chesbrough and Teece, 1996). In particular, long term growth could be jeopardized by an excessive focus on short term results, incremental innovations, and therefore shortermism of the R\&D investment (Calderini and Garrone, 2001). These considerations lead to two open research questions, such as how to measure this shortermism phenomenon (in the already cited Calderini and Garrone, 2001, the authors use publications and patents), and whether the continuous disinvesting in research and the growing focus on development, could lead to undesired long term effects (Godoe, 2000).

\section{Technology transfer and the transfer of human capital: the case of $\mathrm{CRF}$}

\subsection{Background}

Centro Ricerche Fiat employs nowadays more than 900 workers, had revenues of about $€ 111$ millions in 2002, and is one of the 12 sectors which compose the Fiat Group. ${ }^{1}$ Created in 1976, since $1979 \mathrm{CRF}$ is an independent centre of the Fiat Group, which means that it can autonomously take strategic decisions. At corporate level, Fiat maintains the definition of economic and financial rules for the management of human resources. CRF's $€ 25$ millions book capital is completely owned by the other sectors of the Fiat Group, with Fiat Auto, Magneti Marelli and Iveco owning the largest shares.

The degree of independence of CRF from the Fiat Group can be first appreciated by looking at the composition of its turnover. Indeed, about $50 \%$ of CRF's turnover comes directly from Group's orders, while the remaining $50 \%$ comes from external sources. This latter is then sub- divided into public funds received for the participation to national and European research programmes, and transfers from firms external to the Fiat Group - especially SMEs - for technological services. Over time, the degree of independency from the mother company has constantly increased, mainly due to a precise strategic choice. Indeed, the fall in world demand that the automotive sector experienced in 1993 has clearly shown that the whole sector is subject to demand fluctuations, and that having strict economic linkages with only one sector could reveal a very risky strategy.

The role of CRF within the Fiat Group, and its increasing independence from the mother company, are also the result of relevant historical events. In 1993, most Fiat Sectors reacted to the industry's crisis by refocusing their activities and by reducing the overall number of workers. CRF took the opposite direction. CRF did not reduce its activities or fire researchers; rather, it tried to enlarge the sources of revenues, by increasingly taking part to publicly-funded research programmes, and by offering its services to customers external to the Fiat Group. This strategy was mainly the result of a long-term vision of its top management. The early success of this strategy gave CRF a sense of independence and dynamism much greater than what the simple budget figures could imply, and allowed CRF to follow a path of expansion and growth.

As for technology transfer strategy, it is mainly the result of choices operated by the Fiat Group. On the one hand, CRF receives from the mother company and from other firms belonging to the Fiat Group only 'finalized' orders. In turn, funds received from this source cannot be employed in long-term activities of exploration of new research trajectories. On the other hand, the independence of CRF from the Group forces CRF to adopt a market-based approach of continuous improvement. In the words of a widely cited CRF slogan, technology transfer activities become 'CCCP - Competitiveness for Customers at Competitive Prices'.

\subsection{CRF's organization and 'exploration' strategy}

The design of CRF's organization responded to the objectives of technology transfer and exploration of long-term research trajectories. Following a major restructuring in 1998, CRF has been organized in a matrix-form, composed of ten 
technological areas (aggregated in three divisions - vehicles, engines and other technologies) and six staff areas. Whereas the ten technological areas identify CRF's competencies (mainly focused on automotive and transport sectors), the six staff areas respond to the need of organizing those competencies according to specific strategic choices.

Among the various staff functions, Research Promotion is a key activity in pursuing both exploitation and exploration strategies. First, it identifies, from an organizational point of view, the strategic focus on research transfer. CRF's transfer policy is to develop products, processes and technologies to be effectively transferred to the clients. This transfer process is entirely planned at the beginning of a research project, which is usually not launched unless the expected outputs and the related customers' advantages are clearly defined. Hence, each research project is composed of a plan of action, which is part of a major activity plan.

Second, the Research Promotion function plays the role of facilitating CRF's participation in publicly-funded research programmes. In particular, this function's role is to create an international research network to be activated when CRF intends to take part in research programmes promoted by the European Union or other governmental authorities. Since the creation of this function, CRF's participation in national and European research programmes has constantly increased. At the EU level, from 1991 to 1996, Fiat (through CRF) has become the European car producer with the highest number of projects approved and financed within the BriteEuram programme (see Table 1 for the last two years). During the 1999-2002 period, 198 research projects promoted by CRF have been approved and funded within the Fifth Framework Programme. Similar results were also obtained for the Competitive Growth and IST programmes.

This function plays a key role in CRF's strategy, for two main reasons. On the one hand, by participating in publicly-funded research programmes, CRF strengthens its financial (and strategic) autonomy from the Fiat Group. Indeed, the share of this source of revenues in CRF's budget has constantly increased over the last years. On the other hand, by participating in these programmes, CRF reduces the share of revenues received on specific orders - such as orders from the Group, and from some external firms - which usually consist of short-term applied research activities. In doing so, CRF can partly spend its resources on longer-term research
Table 1. Participation to the Brite-Euram programme (1995 and 1996) and to the 5th European Framework Programme (automotive Eucar projects).

\begin{tabular}{lccc}
\hline Car manufacturer & $1995(\%)$ & $1996(\%)$ & 5th FP \\
\hline Fiat (Crf) & 26 & 30 & 25 \\
DB/DC & 19 & 17 & 18 \\
Renault & 10 & 15 & 14 \\
PSA & 10 & 8 & 8 \\
Volvo & 9 & 10 & 12 \\
BMW & 9 & 8 & 3 \\
VW & 9 & 5 & 9 \\
Rover & 3 & 5 & - \\
Opel & 3 & 1 & 2 \\
Ford & 2 & 1 & 8 \\
Porsche & - & - & 1 \\
Total & 100 & 100 & \\
\hline
\end{tabular}

Source: our elaboration on Deiana (1996) and Crf.

projects, not directly finalized to produce specific outputs, but that allow CRF to explore new potentially innovative technological trajectories.

\subsection{The 'exploitation' phase}

The technology transfer strategy pursued by CRF is composed of different phases. Two of the most relevant ones are: (a) the search for 'proper' clients; (b) the development of 'proper' products (Michellone, 1995). CRF usually makes a deep analysis of these phases before starting any transfer process, in order to exactly identify concrete opportunities, the means by which to transfer research results, and the existence of strategic constraints.

CRF's strategy primarily derives its strength from a clear focus on customers. Unlike the common behaviour of many research centres where the commercialization of outputs is taken into account only after having obtained research results, CRF follows a different path. The identification of customers and their needs represents the first, initial phase of the process, and research activity follows at a later stage. Results only come at the end.

At the same time, the focus on customers has a deeper meaning. In many firms (especially SMEs), the introduction of innovations and new technologies often represents a drastic change in their organization, routines and capabilities. This means that CRF needs to identify the proper persons within customers' organizations in order to start an effective interaction. CRF's strategy is to make a distinction between macro- and microclients. Macro-clients are usually identified in the clients' top managers (the entrepreneur, in the case of SMEs), who are among the first to 
perceive technological needs and are interested in financing an innovative project. On the contrary, micro-clients are identified in those groups of people within each firm who will have to manage - and directly pay for, in some cases - the innovation. While the former have an active role in the process, the latter have often a passive one. Thus, the distinction between these two categories of clients becomes relevant in order to define the 'price' that each of them will be asked to pay for the innovation (see Figure 1).

The price macro-clients have to pay is more than the expense of R\&D activities, and comprises the costs of additional investments and organizational changes needed to transform the introduction of a technological innovation into competitive advantage. On the contrary, microclients do not pay a 'monetary' price for the introduction of a technological innovation. The more radical the technological change, the higher the price they have to pay in terms of new skills, competencies and knowledge they have to learn and adopt. The adoption pattern has in this case strong emotional features, and a complete success can be guaranteed only by reducing obstacles to the transfer, and by avoiding the 'not invented here' syndrome.

Then, in order to define the 'proper' output to be offered to customers, CRF has first to identify customers' needs. However, in the case of complex high-tech products, customers might have unexpressed requirements, or might not have the capability to exactly define outputs' characteristics. Both expressed and latent needs have to be analysed in order to obtain success in the research activity (Tidd et al., 1997). In such a case, a strict developer-user interaction is normally required (Leonard-Barton and Sinha, 1993). Hence, CRF

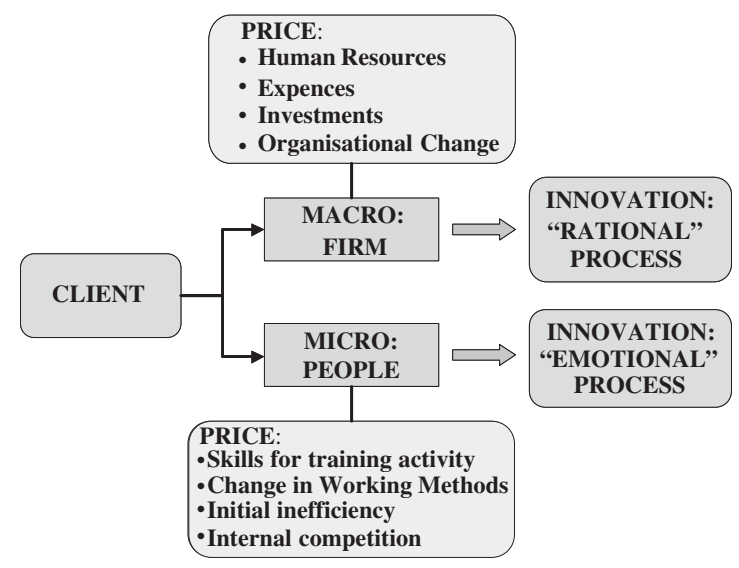

Figure 1. Segmentation of customers.

Source: our elaboration on Michellone, 2001. pays attention to a correct specification of the 'product chain', by using techniques such as Quality Function Deployment (Burn, 1990). These techniques help firms to translate customers' needs in technical and functional specifications to be used in product development.

CRF uses a four-level approach to define products (Michellone, 1995). The first level corresponds to generic products, which satisfy minimal customer's expectations, and include basic requirements. For example, customers will ask CRF's respect of development costs and time, but also of functional specifications - in terms of quality and reliability. At the second level, CRF defines the expected product, which both satisfies customer's minimal requirements and its (latent) expectations. At this level, product definition has to take into account its impact on customer's investments, and managerial and organizational change. The third level - integrated product introduces competitiveness. The goal is to integrate technical and technological dimensions with the market dimension, in order to increase the probability of success for those firms adopting the new technology. This requires CRF to intervene in all relevant aspects of firms' organizations, especially by interacting with micro-clients inside organizations. Finally, at the fourth level, CRF defines the potential product. The basic idea is that 'customer's customers' have to be taken into account, so that by introducing the new technology, CRF's customers can actually respond to their customers' needs.

In sum, CRF's effort is to define products at the fourth level. But this implies relevant technological, organizational and managerial effort. CRF's researchers are required not only to integrate know-how and competencies from different technological areas, but also to analyse the complex environment in which customers usually operate. Indeed, customers' success depends on the fact that their networks of suppliers, distributors, and other external agents can positively react to changes induced by the new technology. In turn, CRF's success is strictly related to its capacity of preventing these changes, and the tensions that will emerge with the external system of relationships.

\subsection{Knowledge transfer and the transfer of human resources}

CRF's attention to technology transfer and to the proper definition of outputs to be transferred is 
paralleled by similar attention to the management of human resources. Indeed, CRF's transfer process towards customers is often complemented with the transfer of human resources, i.e. of those CRF's researchers actively involved in the development of the technology to be transferred. The transfer of human resources represents the most complete form of technology transfer, since together with the researchers all their tacit knowledge is transferred as well. In this sense, cognitive problems in technology transfer are almost completely resolved when transferring human resources. However, this also creates some problems for CRF, concerning the loss of specific technological competences, and the management of researchers' turnover. Thus, in many cases, the transfer of human resources is planned at the beginning of the transfer process, for example by means of coordinated training programmes. For instance, many young researchers that are initially involved in new research projects and are directly trained for those projects, are then transferred with the research project to the client firm. In this, CRF satisfies an institutional task within the Fiat Group: that of creating relevant human capital.

Advantages of this approach are twofold. From the customer's viewpoint, the transfer of human resources makes technology transfer completely effective. Indeed, all tacit knowledge and know-how is transferred to the customer, which realizes that researchers have been trained on that specific technology. From the CRF's viewpoint, that same researcher who is transferred to a customer represents the future preferred interface between CRF and the customer itself, and allows CRF to create even stronger linkages with it. In turn, this approach increases customer's loyalty, as it creates mechanisms of cognitive and organizational lock-in, and increases customer's costs of moving to different suppliers.

However, this approach creates internal problems with regard to the management of human resources. CRF's reaction to this problem is to constantly map its internal competencies, in order to identify those that can be transferred, and those that have to be acquired. Following Hamel and Prahalad (1994), CRF makes a distinction between core competencies (that create a distinctive value to the firm in the long-run), standard competencies (that can be easily found in the external market), and actual competencies (that maintain and increase CRF's competitiveness of actual products and technologies).

It is worth noting that actual competencies are usually transferred to external customers. Their presence is a key competitive factor for CRF concerning actual products, processes and methodologies, but not in the long-run. In the long-run they have either to be sold or re-trained. At the same time, they represent a key factor for competitiveness of CRF's customers, and often become the core competencies of customers. In turn, by transferring those resources to customers, CRF obtains a direct economic benefit, and an indirect benefit in costs reduction for avoiding future re-training programmes.

By adopting this approach, CRF annually transfers a relevant share of its researchers to external firms. In the last ten years, the average annual turnover of researchers has been about $8.9 \%$, the share of employees with a Laurea degree has been about $55 \%$, and their average age has been 33 (Michellone, 2001). CRF manages this high turnover by following two different sets of solutions. On the one hand, the size of the organization is virtually increased, by signing collaborative agreements with about 650 partners and suppliers, towards which about $25 \%$ of annual budget is usually spent. Furthermore, CRF annually supports more than 100 university students and more than 100 post-graduate students who spend part of their time at CRF to complete their Laurea thesis or for a stage period. Most of these students are then hired by CRF itself or by CRF's customers, hence feeding the process of interaction between CRF and its customers described above.

\section{Technology exploitation via spin-off creation: the case of TiLab}

During the nineties, research centres operating in the Tlc sector went through relevant changes for which two main interpretations are possible. First, the deregulation process led to the emergence of new actors, which made the market more fluid and complex; often incumbent firms faced for the first time a real competitive environment. Moreover, profitability and competition in the new business sectors, and the necessary ability to adopt new technologies, led to a stricter control of overhead costs, and in particular those related to $\mathrm{R} \& \mathrm{D}$ activities. The former monopolists are today trying to find new ways to achieve or keep profitability in a rapidly changing market, and are therefore setting new demands, objectives and pressures on their $R \& D$ centres.

As a consequence, $R \& D$ centres are trying to find additional financial resources, especially from outside their industrial group, which in 
many cases is diminishing available resources, and to exploit externalities from R\&D activities. New business models and competencies are becoming significant and used in the sector, although a variety of technology strategies are being followed in various large Tlc companies. Among these, efforts have been made for the development of spin-off companies and incubators, as well as for the setting up of specialized competencies for the marketing of inventions. Some research centres are also trying to develop new venture capital activities to detect and attract new ideas, technologies or business opportunities.

\subsection{Background}

Telecom Italia Lab (TiLab) is the company of the Telecom Italia Group devoted to promote innovation in the ICT field through the development of new technologies and the definition of new business opportunities by means of venture capital operations. It was created in 2001 by merging the pre-existing Telecom Italia research centre (the large and consolidated Cselt - Centro Studi E Laboratori Telecomunicazioni) and the young Telecom Italia 'Venture Capital \& Innovation' business unit, plus three other smaller research laboratories belonging to the same group - i.e. the Future Centre in Venice (Italy), the Consumer Lab in Rome (Italy), and the Technology Observatory in San Francisco (CA). Today the centre employs 1100 people; significant restructuring is under way to integrate TiLab in the new structure of the Pirelli Group and in particular to create synergies with Pirelli Labs.

Up until 2001, the focus of Cselt had been to promote research, experimentation and qualification in the telecommunication and information technologies sectors. Its purpose was to do research and provide the best technologies and competencies for all the companies of the group. In 1999, Cselt personnel consisted of about 1,200 researchers. Its budget was about 280 billion Lira (about 140 million Euros). The flow of revenues from companies outside the Telecom Italia group grew in the last years (see Figure 2). This is an important proxy for the level of market-oriented activities performed by the Centre.

During the nineties, Telecom Italia undertook radical changes which affected the role and organization of its research labs. The first radical change was the privatization of the former public monopolist - although the Italian State retained golden-share privileges - and the consequent

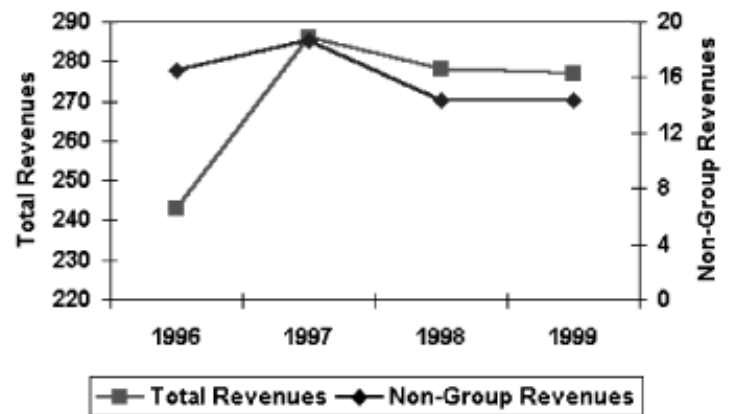

Figure 2. Cselt Revenues (billions Italian Liras). Source: TiLab.

creation of the Telecom Italia Group. A second important event was Roberto Colaninno's acquisition of the group in February 1999. Colaninno was the CEO of the Omnitel/Tecnost Group, the biggest competitor of Telecom Italia. Antitrust laws prevented the creation of a new (private) quasi-monopoly, and Omnitel had to be sold. Colaninno's adventure in Telecom Italia lasted two years. A new buyout in 2001 led the industrial group Pirelli into control of Telecom. The Italian government chose not to interfere with these changes.

During this period, Cselt/TiLab enlarged its mission and changed its organization. In 1997 a functional organization was introduced, and 11 areas were defined. Gradually, the 1997 organization changed into a 'systematic solution', with a project-based division of labour, which allowed Cselt to answer more efficiently to the interdisciplinary demands coming from the other companies of the Group. The capacity to offer interdisciplinary and systemic solutions was clearly identified as one of the main asset of the lab.

In March 2001 another important change in Cselt/TiLab structure was introduced, with the goal of rendering it a real 'innovation company', able to develop and exploit the multiple and complex activities of the Group. Tilab was reorganized in three business areas: Technology Integration \& Research, Venture Capital, and ICT Skill Building. The objective of these changes was to create an extremely flexible organization, able to integrate new realities, through the creation of autonomous unities, partnership with external subjects, and financial participation to new entrepreneurial activities. Tilab has also become the incubator for innovative initiatives, both from internal scientific and technological activities, or only indirectly related to them, such as new strategic alliances, new business opportunities, 
and so on. This activity, however, is not particularly successful.

One of the most interesting examples of activities that emerged from these choices was Loquendo. The project started in February 2001 with the objective of exploring new business possibilities and exploiting the competencies of Cselt in the important field of voice recognition. TiLab management decided to allow Loquendo to operate as an independent company with proprietary technology not commercialized by Telecom Italia. Customers for Loquendo are today large firms, other telecom operators and Internet providers. The most important application was VoxNauta, which enabled the access and the browsing of databases and the Internet through a voice recognition system.

Besides such activities, TiLab kept providing more traditional services to the Telecom Italia Group, such as studies and feasibility tests, experiments, and normative specifications. However, TiLab focused its activities on the exploitation of internal competencies for the generation of new revenues. In the following sections we will focus on these activities.

\subsection{The observatory and technological collaborations}

As it has been described, the setting up of TiLab led to substantial changes for the venture capital business unit of Telecom Italia, and new forms of technological transfer within the Group. Cselt had always been an 'observatory point' for new trends and technologies in the ICT sector. During the reorganization phase that we are describing, these observatory activities have been strengthened with the introduction of new programmes, resources and infrastructures that allowed TiLab to interact more directly with organizations outside the group. There are two categories of possible interlocutors. First, SMEs operating in the ICT sector. Second, other possible 'emerging talents'. The goal was to hunt for partnerships (or acquisitions) and placements in TiLab.

In pursuing this goal, Tilab decided to offer assistance to the start-up and development of SMEs operating in the ICT sector. An important aspect of this technology transfer strategy was to exploit the spillovers from internal research activities. Loquendo represented one of the first initiatives in the field. Moreover, the goal was to offer universities and SMEs financial instruments, competencies and infrastructures to develop entrepreneurial ideas (see Figure 3).

The definition of a new Venture Capital Area was the final achievement of this business model. However, the risks and opportunities connected with venture capital activities are complex. Expected financial returns have to be clearly identified, and specialized operators are needed, in order to fully evaluate the risks involved.

The role of a research centre that operates on the venture capital market is to be an early spotter of emerging trends, technologies and possibilities. This is possible only if the observatory is located close to the sources of innovation, like universities, customers, users and other competitors. Such a position allows the research centre to reduce

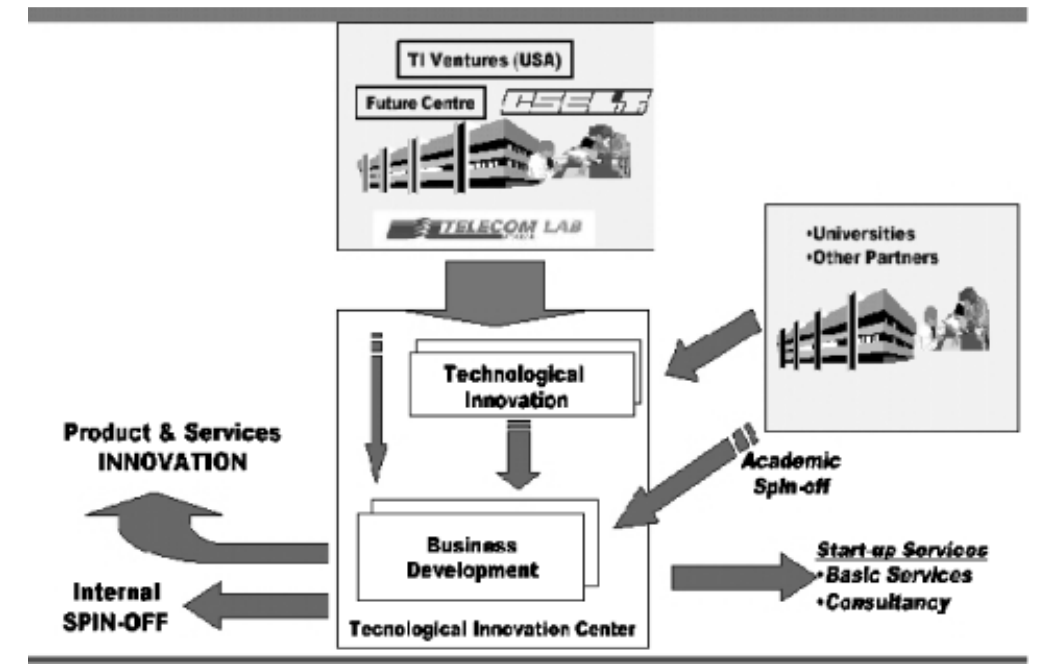

Figure 3. The new technology transfer model.

Source: TiLab 
transaction costs related to the exchange of information, knowledge, services and innovation.

Such a flow of know-how is indeed bi-directional, and needs to be built with a long-term perspective. It is therefore useful to have structures that are able to interact and use resources outside the group and to transform a vision or a clue into scenarios and business opportunities which can be developed inside or outside the Group. This is indeed the task that Tilab was assigning to the Future Centre in Venice. The role of this Centre was to analyse the market, understand and translate demands coming from potential customers, promote and sell ICT solutions available like shelf innovations.

Within the framework of these structural changes, the role assigned to the Future Centre could be regarded as a point of reference for firms outside the Group that wanted to interact with TiLab or use some of the technologies and products of TiLab research activities. The Centre could rely on the consistent portfolio of innovations developed throughout the years by Cselt, and the new (market oriented) projects started by Tilab.

\subsection{The monitoring and creation of new competences}

The focus on internal human resources has to be a priority for Tilab, since the costs of deploying human resources at a research centre has increased in recent years. Financial incentives integrated the already existent non-monetary benefits typical of the research activity, such as a flexible working environment, a constant update programme, and the possibility to be part of the peer recognition system.

In general terms, the presence of a high turnover of human resources in a research lab has both positive and negative consequences. Indeed, new entries carry with them new ideas and also important links with outside institutions. The flow out of personnel is moreover useful if directed toward other companies of the same group. The research centre in this case 'forges the competencies' needed for the management of the group.

High turnover has however other more disturbing consequences and quite relevant costs. In the first place, it becomes more difficult to manage long-term projects. Moreover, the spillover of know-how and key-competences might favour competitors rather than other companies of the group.
Traditionally, Cselt turnover has been rather low, in spite of the enormous pressures of the market and the presence of new actors hunting for competencies. The fact that the Centre was located in Turin could partially explain this fact, since in most cases, Cselt employees would need to move away from the city in order to accept a competitive job offer elsewhere. Geographic positioning represents, therefore, a natural barrier to the spillover of precious human resources.

In 1999, the management implemented relevant changes to the professional system of the firm, qualifying three different roles, the technical leader, the project manager, and the competence (or cluster) manager. These reforms reflected the adoption of a matrix model of the business units. Moreover during the same year, Cselt started a programme to facilitate mobility within the various areas of the Centre, and technical update.

Besides the activities of traditional competence retention, in 2001 Tilab started to support internal spin-off processes and incubator structures, in order to promote a sort of 'controlled spillover' of its personnel. Researchers were given the possibility of developing their projects in a quasi-market environment, with the necessary autonomy, but not with all the risks connected with normal entrepreneurial activity.

The strategy for talent scouting changed as well. A new branch, called ICT Skill Building experimented with new ways of getting contacting and entering the Group, much more flexible and 'customized' than previous ones. Besides the possibility of internships, graduation/ $\mathrm{PhD}$ theses, collaborations with other research institutes and universities, initiatives such as Dreambay were used to attract young people with an entrepreneurial aspiration and sound technical background, even if not necessarily connected with academia. Furthermore, another task was to develop initiatives to strengthen ICT competences already present inside the Group. Priorities for 2001 were e-learning, e-university and publication of technical newsletters.

\section{Conclusions}

The cases of CRF and TiLab analysed in this study confirm that the definition of strategic and organizational issues in large $R \& D$ centres is a complex, multifaceted process. A number of factors influence each other and contribute to determine the overall framework. Some of these factors have to do with external conditions, such 
as the emergence of new technological disciplines and paradigms, the changes in the structure of specific industrial sectors, changes in demand conditions, important 'historical' events, and so on. Some other factors are more closely related to internal conditions, and include corporate governance assets, top managers' ability to identify and implement organizational solutions, the influence of leading individuals in determining strategies for the laboratories, etc.

Despite this common framework, the two cases differ in the operational solutions that have been implemented in order to face those changes. On the one hand, TiLab management decided to abandon the model of the traditional research lab, in favour of a system integration approach. The goal was indeed to create an innovation company, whose core productions were innovations and innovation management. In this new business model, the attraction and retention of key human resources, and the creation of new business opportunities through controlled spinoff processes became a relevant feature. Differently, CRF has focused its attention in defining efficient procedures for the management of technology transfer, mainly to local SMEs. In this, it has been very innovative in finding new ways to analyse customer's needs, to develop proper products, to transfer human capital, and to manage researchers' turnover.

However, a deeper analysis shows that the difference between the two cases is even bigger. Basically, CRF has managed to find out through hard bottom-up work - an original model which guarantees its existence and even growth in periods characterized by decreasing investments in R\&D. Particularly severe observers might argue that the obsession with customers' needs can be an obstacle to proper effort in high-risk, long-term research areas, that should be achieved especially through publicly funded research projects. The continuous renewal of research staff is another strategic asset where scientific and technological competencies become quickly obsolete for state-of-the-art research purposes, but are certainly valid for applicative tasks in manufacturing firms. It is rather curious to notice that all this has happened without direct intervention from the corporate level of Fiat, which somehow limited its responsibilities to 'accepting' the new model. Several indicators show that the CRF model is now consolidated; it might well be changed in the future or show relevant weaknesses, but it has been well assimilated and understood within the research centre and among partner companies, as well as among top management which is at present trying to relaunch Fiat in the international market.

The Cselt/TiLab story has not been characterized by an equally clear, consistent and longlasting model. The changes which have taken place in the TLC sector and specifically in the R\&D centre's ownership have not allowed the emergence of a robust strategic direction. Top management in the Telecom Group has probably spent a lot of effort in understanding how to deal with the TLC sector, and only after that has tried to devise a strategy for the R\&D lab. Nonetheless, a few concepts and changes became quite clear among researchers who in the past had been asked to search for scientific excellence. Strategy building and behaviour alignment has been so far rather difficult in TiLab. First of all, because during Colaninno's period there was probably no clear idea about what to do with a large R\&D centre. Second, because in the last months of Colaninno's period and in the early Pirelli period, the project of joining together venture capital competencies and assets, and scientific and technological resources has become much clearer, but would require an even stronger commitment in communication, diffusion and incentives for researchers. In a moment when the transition in TiLab required still more resources and open support from the new top management, recent changes seem to suggest that indeed the intention is to change, once again, strategy, and to refocus the activities of the 'innovation factory' towards more traditional R\&D services for the Group. Further analysis on the future performance of Tilab and the Telecom Italia Group will be needed to fully appreciate the direction and success of these choices.

The different nature of technologies, services and products in the two cases also has an influence on the solutions adopted. In CRF most technologies are independent and standalone, so that research units can easily be set up and abandoned. In TiLab, the more pervasive systemic nature of products and services in TLC makes it harder to 'pack and sell' specific outputs, so that the more difficult solution of starting spin-off companies has been identified.

The success of these strategies in the long-run is not completely clear. But it will definitely depend upon the capability that the two organizations will show in order to create a correct balance between short-term and long-term objectives, between exploration of research results and exploitation of new scientific and technological paths. 


\section{Acknowledgements}

We would like to thank GianCarlo Michellone, Dario Monti, Massimo Casali, Gabriella Marinsek, Maria Onida, Elena Sinchetto, Paolo Volpi and the CRF's staff for the deep and interesting discussions about their organization. Our gratitude also goes to the TiLab staff members whom we had the opportunity to meet and work with: Fulvio Faraci, Roberto Saracco, Francesca Mondello, Aurora Amato. Fabrizio Cesaroni acknowledges the Italian Consiglio Nazionale delle Ricerche (CNR) for financial support, Project N. CNRG00B857.

\section{References}

Burn, G.R. (1990) Quality function deployment. In: Dale, B.G. and Plunkett, J.J. (eds), Managing Quality. London: Philip Allan.

Calderini, M. and Garrone, P. (2001) Liberalisation, industry turmoil and balance of R\&D activities. Information Economics and Policy, 13, 199-230.

Chesbrough, H.W. and Teece, D.J. (1996) When is virtual virtuous. Harvard Business Review, January/ February, 65-73.

Chiesa, V., Giglioli, E. and Manzini, R. (1999) R\&D corporate planning: selecting the core technological competencies. Technology Analysis \& Strategic Management, 11, 2, 255-270.

Cooper, R. and Wootton, A.B., et al, (1998) Requirement capture: theory and practice. Technovation, $\mathbf{1 8}$, 8-9, 497-511.

Deiana, M. (1996) Verso nuovi modelli della R\&S. I casi: Europa Metalli, CSELT, CRF', Laurea Thesis. Pisa: University of Pisa.

Duysters, G. and Hagedoorn, J. (1996) Internationalization of corporate technology through strategic partnership: an empirical investigation. Research Policy, 25, 1-12.

Evangelista, R. and Sirilli, G. (1998) Innovation in the service sector results from the Italian statistical survey. Technical Forecasting and Social Change, 58, 3, 251-269.

Godoe, H. (2000) Innovation regimes, R\&D and radical innovations in telecommunications. Research Policy, 29, 1033-1046.
Granstrand, O. (1999) Internationalization of corporate R\&D: a study of Japanese and Swedish corporations. Research Policy, 28, 2/3, 275-303.

Hamel, G. and Prahalad, C.K. (1994) Competing for the Future. Boston: Harvard Business School Press.

Leonard-Barton, D. and Sinha, D.K. (1993) Developer-user interaction and user satisfaction in internal technology transfer. Academy of Management Journal, 36, 5, 1125-1139.

Lera, E. (2000) Changing relations between manufacturing and service provision in a more competitive telecom environment. Telecommunication Policy, 24, 413-437.

Michellone, G.C. (1995) Organizing science: constraints and new challenges. ATA - Ingegneria Automotoristica, 48, 12, 675-684.

Michellone, G.C. (2001) Dalla ricerca all'industria: Miti e realtà per le PMI. L'esperienza CRF, paper presented to the conference Link Day. Tecnologie, Imprese, Capitali, Lecce: Associazione degli Industriali, 2 March.

Mowery, D.C. (1995) The boundaries of the US firm in R\&D. In: Lamoreux, N.R. and Raff, D.M.G. (eds), Coordination and Information. Chicago: Chicago University Press.

Pennings, E. and Lint, O. (1997) The option value of advanced R\&D. European Journal of Operational Research, 103, 83-94.

Ransley, D.L. (1994) Do and dont's of R\&D benchmarking. Research Technology Management, September-October, 50-56.

Rao, U.B. (2000) Manage corporate R\&D to be costeffective for success. Chemical Business, 14, 11/12.

Rush, H. and Hobday, M., et al, (1995) Strategies for best practice in research and technology institutes: an overview of a benchmarking exercise. $R \& D$ Management, 25, 1, 17-31.

Tidd, J., Bessant, J. and Pavitt, K. (1997) Managing Innovation. Integrating Ttechnological, Market and Organisational Change. Chichester: Wiley.

Vonortas, N.S. and Safioleas, S.P. (1997) Strategic Alliances in Information Technology and Developing Country Firms. Washington DC: World Bank.

\section{Note}

1 See: http://www.fiatgroup.com/fiat-centenario/ settori/crf.html. 